\title{
The Iron Brake Dust Age and the Female Advantage
}

\section{William J Rowe*}

\section{Former Assistant Clinical Professor of Medicine, Medical University of Ohio, USA}

*Corresponding author: William J. Rowe, MD FBIS FACN, Former Assistant Clinical Professor of Medicine, Medical University of Ohio, Toledo, 1485 Bremerton La, Keswick, Virginia 22947, USA, Tel: 4349840079, E-mail: rowefemsinspace@gmail.com

The iron brake dust age began with the automobile in the 1890's. Until recently, although air pollution was considered a risk factor for hypertension, the studies lacked statistical significance and were considered controversial [1]. However, a Japanese study, also published in the same year, 2016, showed that the key tracers of brake wear particles for example, iron and copper, were at emission levels comparable to traffic-related atmospheric environments [2].

I have pointed out with recent editorials $[3,4]$ that the particulate matter, released from iron brakes is literally killing us because it is conducive primarily to hypertension. Furthermore, just as lunar investigators discovered that the quantity of iron particulate matter could be determined with magnets [3,4], recent studies have shown with magnets, that there may be little or no protection from outside iron particulate matter reaching indoors [5]; this suggests for example, that exercise on a treadmill, provides little or no protection versus running outdoor. Equally disturbing, is that with exposure to traffic, we are at risk from myocardial infarctions [6]. Furthermore, our risk from iron, may begin in childhood, based on the study in the Netherlands of 12-yearold's which showed that -- with exposure to iron-- there were significant elevations of diastolic blood pressures, portending hypertension in adulthood; similarly, Neil Armstrong returned from his historic mission, with extraordinary elevation of his diastolic blood pressure [3].

I have emphasized the advantages females have in Space, exemplified by the case for an all - female crew to Mars [7]. The incidence of endothelial injuries and the mortality rate is over six times higher in males than females under age 35 .

In addition to estrogen, with marginal intakes of magnesium (Mg), the levels are significantly higher in females; this is particularly advantageous since $\mathrm{Mg}$ deficiencies are so common, worldwide, existing in at least $60 \%$ of those in the United States. I believe correcting magnesium deficiencies may prolong life [8]. Both estrogen and $\mathrm{Mg}$ are antioxidants and calcium blockers, enhancing endothelial function, repair and angiogenesis. Long before atherosclerosis develops, an inflammatory process adversely affects the endothelium. This process is more likely to occur in men than in women by the third and fourth decades of life. Coronary artery disease may begin in males by age 11 . The menstruation advantage with monthly loss of 30-50 cc of blood along with iron and in turn, protection from oxidative stress, provides a considerable advantage regarding tolerance to the release of iron particulate matter from brakes. How long will the "Iron Brake Dust Age" last? Until effective legislation occurs-- perhaps decades from now. A frontpage story in a prominent, widely circulated newspaper, should do wonders. It seems to me rather strange that this risk hasn't been published until recently, since we have known about the hazards of iron-induced oxidative stress for decades; particularly, the hazards of inhalation of iron particulate matter since Man visited the moon almost fifty years ago. How much longer must we wait?

\section{References}

1. Cai Y, Zhang B, Ke W, Feng B, Feng B, et al. (2016) Association of short term and long-term exposure to ambient air pollutants with hypertension. Hypertension 68: 62-70.

2. Hagino H, Oyama M, Sasaki S (2016) Laboratory testing of airborne brake wear particle emissions using a dynamometer system under urban city driving cycles. Atmosph Environ 131: 269-278.

3. Rowe WJ (2017) Neil Armstrong's lunar diastolic hypertension. J Hypertens Manag 3: 029e.

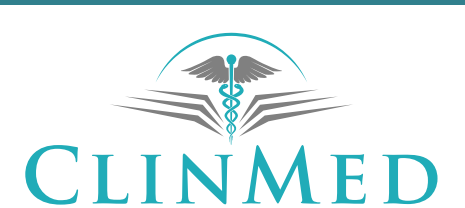

INTERNATIONAL LIBRARY

Citation: Rowe WJ (2018) The Iron Brake Dust Age and the Female Advantage. J Hypertens Manag 4:035e. doi.org/10.23937/2474-3690/1510035e

Accepted: August 06, 2018: Published: August 08, 2018

Copyright: (c) 2018 Rowe WJ. This is an open-access article distributed under the terms of the Creative Commons Attribution License, which permits unrestricted use, distribution, and reproduction in any medium, provided the original author and source are credited. 
4. Rowe WJ (2018) Brake iron dust inhalation, magnesium deficiencies and hypertension. J. Hypertens Manag 4: 031e.

5. Szczepaniak-Wnuk I, Gorka-Kostrubiec B (2016) Magnetic particles in indoor dust as marker of pollution emitted by different outside sources. Stud Geophys Geod 60: 297-315.

6. Peters A, Von Klot S, Heier M, Trentinaglia I, Hörmann A, et al. (2004) Exposure to traffic and the onset of myocardial infarction. New Eng J Med 351: 1721-1730.

7. Rowe WJ (2004) The case for an all-female crew to Mars. J Men's Health and Gender 1: 341-344.

8. Rowe WJ (2012) Correcting magnesium deficiencies may prolong life. Clin Intervent Aging 7: 51-54. 